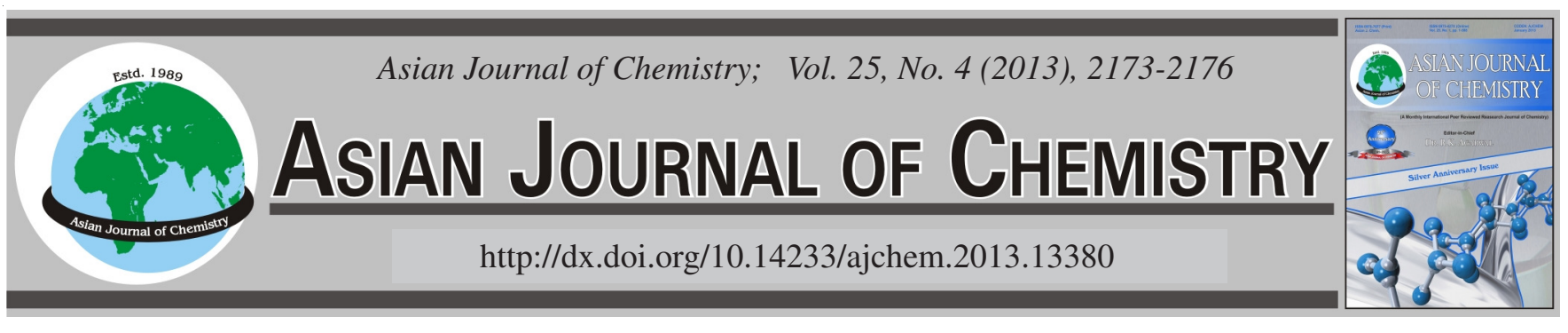

\title{
Adsorption of Basic Yellow 28 in Aqueous Solution by Activated Carbon
}

\author{
Dao Sy Duc ${ }^{1, *}$, NGuyen Bin ${ }^{2}$ and Tran Thi Huyen Trang ${ }^{3}$
}

${ }^{1}$ Department of Chemical Technology, Faculty of Chemistry, VNU University of Science, Hanoi, Vietnam, 19 Le Thanh Tong Str., Hanoi, Vietnam ${ }^{2}$ Department of Chemical Engineering, Hanoi University of Science \& Technology, 1 Dai Co Viet Str., Hanoi, Vietnam

${ }^{3}$ Hanoi Agricultural and Rural Development Department, 43 Ho Dac Di Str., Hanoi, Vietnam

*Corresponding author: Fax: +84438241140; Tel: +84 438253503; E-mail: ducds@vnu.edu.vn

In this study, the coal-based granular activated carbon from Ha Bac (GAC-HB) was used to remove basic yellow 28 (BY 28) from aqueous solution. The structure and surface properties of granular activated carbon from Ha Bac were analyzed by modern methods. Its adsorption capacity was also determined by Langmuir and Freundlich isotherms. Effects of some key operating parameters such as the initial dye concentration, contact time, $\mathrm{pH}$ as well as the dose of granular activated carbon from $\mathrm{Ha} \mathrm{Bac}$ on the dye removal were investigated. The results show that the granular activated carbon from Ha Bac is a good adsorbent for removing basic yellow 28.

Key Words: Activated carbon, GAC, Basic yellow 28, Textile wastewater, Surface properties.

\section{INTRODUCTION}

In Vietnam, textile industry is one of the most important industries contributing to the national economic growth. However, due to the specific characteristics of a complex manufacturing industry that utilizes much water, chemicals, materials etc. The risk of environmental pollution caused by the textile industry is inevitable ${ }^{1}$. Wastewater from the textile industry is one of major environmental problems in Vietnam and many other countries ${ }^{2-5}$. The environmental pollution due to the textile industry is multidimensionally causing serious problems not only to the land mass fertility but also to the natural flora, fauna, as well as the aquatic bodies. Colour is one of the characteristics of an effluent from textile wastewater, caused by dyes, which is easily detected ${ }^{6,7}$. Colour affects the nature of the water and inhibits sunlight penetration into the stream, reduces photosynthetic action.

Most of the dyes are resistant to biological degradation. Removal of dyes from water is very important because the water quality is greatly affected by colour and even the presence of very small concentrations of dyes (less than $1 \mathrm{mg} / \mathrm{L}$ ) in water is highly visible and is considered unpleasant. Besides that, many of these dyes also cause health problems such as allergic dermatitis ${ }^{5}$. Some of these dyes are toxic and suspected to have carcinogenic and mutagenic effects ${ }^{8}$.

Basically, pollutants from wastewater can be removed by physical, biological and chemical methods such as coagulation, advanced oxidation processes (AOPs), biological techniques, adsorption etc. However, dyes are not easily degradable and not easily removed from wastewater by conventional wastewater treatment systems $s^{6,9-11}$. Adsorption has been found to be superior to other techniques for water re-use in terms of initial cost, simplicity of design, ease of operation and insensitivity to toxic substances. Now-days, some materials such as chitin, clay, fly ash and tree fern have been known as good adsorbents for removing dyes in wastewater. Activated carbon has also been accepted as one of the most appropriate low cost sorbents. The application of sorption technique using activated carbon has been investigated $\mathrm{d}^{2,3,5,6,9,10,12-16}$.

In this paper, experiments have been carried out, to determine the sorption capacity of GAC-HB, to remove basic yellow 28 in an aqueous solution. The effects of various operating parameters such as adsorbent dose, concentration of dye, $\mathrm{pH}$, as well as adsorption dynamics have also been studied and discussed.

\section{EXPERIMENTAL}

The adsorbent used in the present study is GAC-HB, the coal-based granular activated carbon was made from coconut shell. The adsorbate used in the experiments was BY28, was purchased from Shimi Boyakhsaz Co., Iran, which is used in the dying procedure of Mua Dong Textile and Garment Company, Hanoi, Vietnam. The molecular structure and physical properties of BY28 were shown in Fig. 1 and Table1 , respectively. 
<smiles>COc1ccc(N(C)/N=C/C2=[N+](C)c3ccccc3C2(C)C)cc1</smiles>

Fig. 1. Molecular structure of basic yellow 28

\begin{tabular}{ll}
\multicolumn{2}{c}{ TABLE-1 } \\
PHYSICAL PROPERTIES OF BASIC YELLOW 28 DYE [Ref. 17] \\
\hline \multicolumn{1}{c}{ Dye properties } & \multicolumn{1}{c}{ Maxilon golden yellow GL 200 \% } \\
\hline Colour index & Basic Yellow 28 \\
Azo group & 1 \\
Type & Cationic \\
Shape & Powder $200 \%$, particular $200 \%$, liquid $200 \%$ \\
Solubility & $80 \mathrm{~g} / \mathrm{L}\left(90^{\circ} \mathrm{C}\right) ; 60 \mathrm{~g} / \mathrm{L}\left(60^{\circ} \mathrm{C}\right) ; 40 \mathrm{~g} / \mathrm{L}\left(30^{\circ} \mathrm{C}\right)$ \\
pH stability & $3-10$ \\
$\lambda_{\max }$ & 438 \\
Mw & $433 \mathrm{~g} / \mathrm{mol}$ \\
\hline
\end{tabular}

Distilled water was used for all solution and dilution. All chemicals used for analytical methods were analytical grade.

Characteristics of adsorbent: The surface area of sorbent and its capillary size were determined by nitrogen adsorption method at $77 \mathrm{~K}$ using Autosorb-1C (Quantachrome, USA). Before measuring the isotherm, adsorbent was heated at 200 ${ }^{\circ} \mathrm{C}$ in vacuum for $2 \mathrm{~h}$. The surface area of GAC-HB was calculated by the BET method using the adsorption isotherm of nitrogen.

The structure of activated carbon was determined by $\mathrm{X}$-ray diffraction method using Bruker D8 Advance X with $\mathrm{CuK}_{\alpha}$ radiation. $2 \theta$ scan angle varies from $10-70^{\circ}$, scan time is $1 \mathrm{~s}$ step, a scanning angle of $0.03^{\circ}$.

Study on dye removal: The sorption capacity of GACHB was tested by Langmuir and Freundlich adsorption isotherm models.

An amount of GAC-HB was added to $200 \mathrm{~mL}$ of basic yellow 28 dye solution. The dose of sorbent, initial dye concentration, solution $\mathrm{pH}$ may be different in different studies. After the mixtures were mixed, the samples were filtered using a coarse cloth filter to remove large suspended particles with the purpose of determining the quality of treated wastewater.

Analytical methods: The colour of dye solutions (both before and after treated) were analyzed using a UV-1650 PC (Shimadzu Co., Japan). A dye solution was scanned from 300$800 \mathrm{~nm}$ so that to determine its maximum absorbance. The colour removal was decided basing on the change of $\mathrm{ABS}$ value at maximum absorbance:

$$
\mathrm{R}(\%)=\frac{\mathrm{C}_{0}-\mathrm{C}_{\mathrm{t}}}{\mathrm{C}_{0}} \times 100
$$

where: $\mathrm{R}, \mathrm{C}_{0}, \mathrm{C}_{\mathrm{t}}$ were colour removal, the concentration of basic yellow 28 before and after the treatment, respectively.

\section{RESULTS AND DISCUSSION}

Characteristics of GAC-HB: The results on the surface characteristics of GAC-HB were shown in Figs. 2,3 and Table2 .

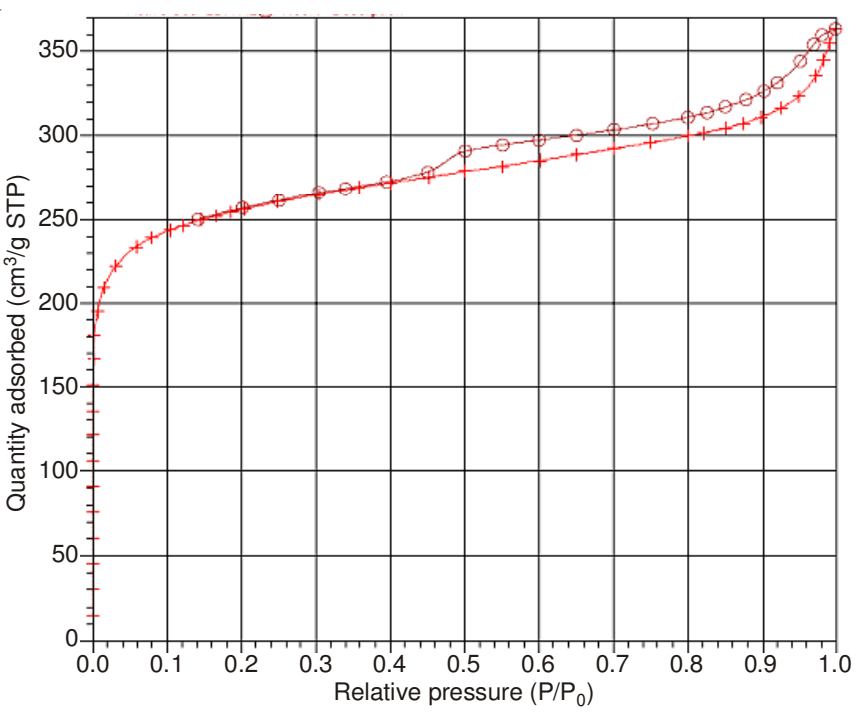

Fig. 2. Adsorption isorthem plot of nitrogen at $77 \mathrm{~K}$ for GAC-HB

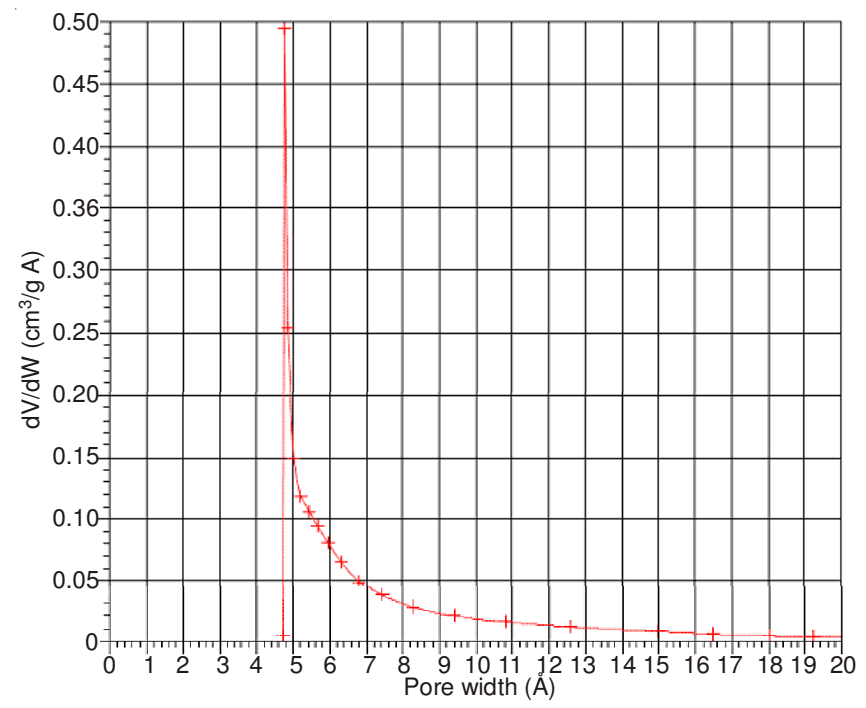

Fig. 3. Pose size distribution of nitrogen at $77 \mathrm{~K}$ for GAC-HB

TABLE-2

CHARACTERISTICS OF GAC-HB

\begin{tabular}{|c|c|c|}
\hline \multirow[b]{2}{*}{ Characteristic } & \multicolumn{2}{|r|}{ Value } \\
\hline & BET & $\begin{array}{c}\text { Langmuir/Horwath- } \\
\text { Kawazoe }\end{array}$ \\
\hline Surface area $\left(\mathrm{m}^{2} / \mathrm{g}\right)$ & 869.6452 & $1102.2048(\mathrm{~L})$ \\
\hline $\begin{array}{l}\text { Micro-pore volume, } \mathrm{cm}^{3} / \mathrm{g} \\
\text { (evaluated from } t \text {-plot equation) }\end{array}$ & & 0.402036 \\
\hline Pore size $(\AA)$ & 23.8832 & $8.360(\mathrm{H}-\mathrm{K})$ \\
\hline
\end{tabular}

The results showed that adsorbent used in this study has a large surface area and micropore structure. The adsorbent was also tested by X-ray diffraction (Fig. 4). Activated carbon has amorphous structure, but there are some crystal structure peaks belong to $\mathrm{CaCO}_{3}$.

Effect of initial dye concentration and contact time: The effects of initial dye concentration and contact time on the treatment process were shown in Fig. 5. As can be seen in the figure, dye removal was found to increase when initial dye concentration decreased. According to the results, adsorp- 


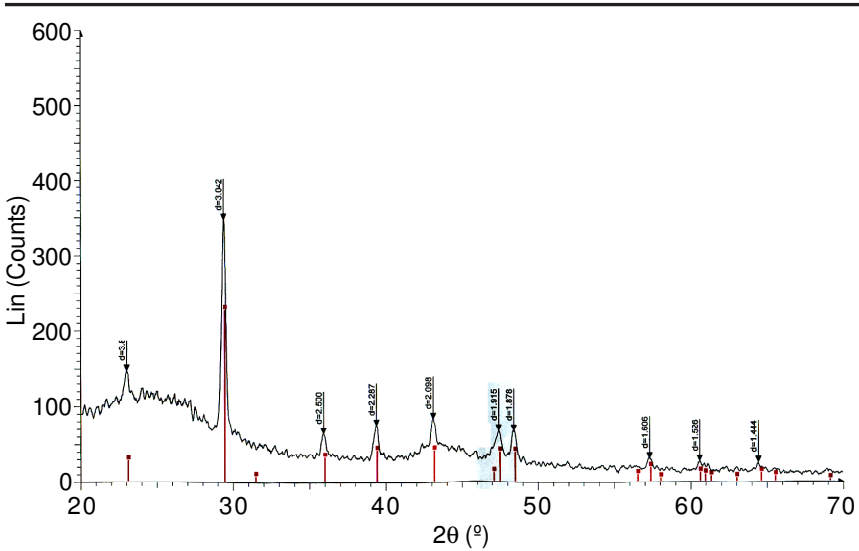

Fig. 4. X-Ray diffraction plot of GAC-HB

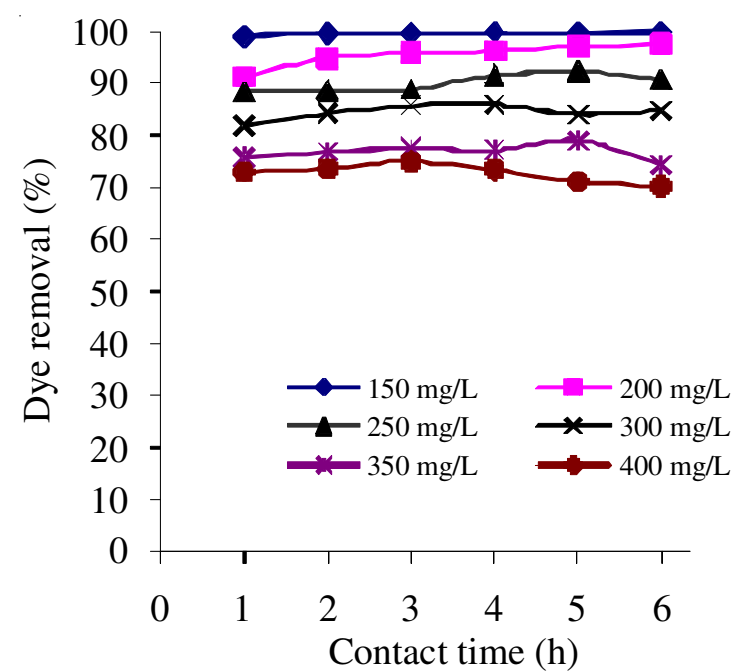

Fig. 5. Effect of initial dye concentration and contact time on the removal of basic yellow 28

tion equilibrium achieved at the contact time of $c a .4 \mathrm{~h}$. At this time when the initial dye concentration increased from 150$400 \mathrm{mg} / \mathrm{L}$, the dyes removal effectivity was decreased from 99.84 to $73.39 \%$.

Effect of mass of GAC: These mass of GAC-HB was changed from 0.05 to $0.225 \mathrm{~g}$. The effects of sorbent dose were shown in Fig. 6.

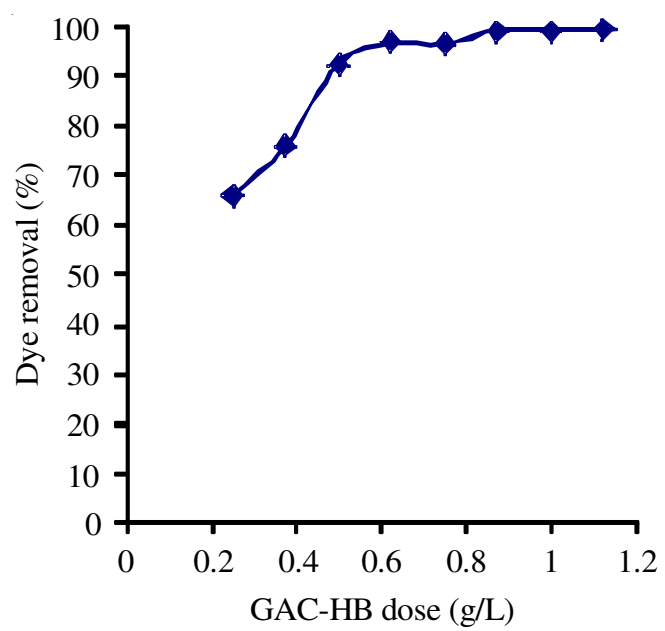

Fig. 6. Effect of sorbent dose on the removal of basic yellow 28
The dye removal effect increased rapidly when increasing sorbent dose from 0.250 to $0.625 \mathrm{~g} / \mathrm{L}$ and then increased slowly until the equilibrium at sorbent dose reaches $0.8 \mathrm{~g} / \mathrm{L}$ (Fig. 6). This is due to greater surface area available for adsorption of dye species in the solution.

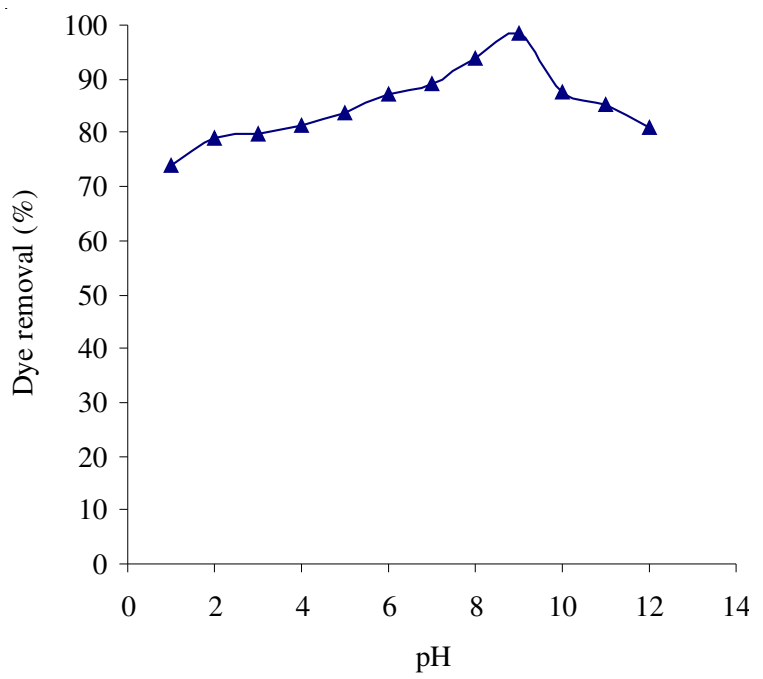

Fig. 7. Effect of $\mathrm{pH}$ on the removal of basic yellow 28

Effect of pH: Basicaly, pH usually has strong effect on the adsorption. In this study, the variation in the adsorption of BY28 was studied in the $\mathrm{pH}$ range of 1-12 and the experimental results are shown in Fig. 7. As can be seen, it is clear that the $\mathrm{pH} 9$ is optimum value for adsorption of BY28 by GAC-HB. Olgun and $\mathrm{Atar}^{1}$, reported that variation of adsorption with $\mathrm{pH}$ can be explained by considering the difference in the structure of dyes and the electrokinetic behaviour of adsorbent. Based on the results, $\mathrm{pH} 9$ is optimum value for removing BY28 by adsorption using GAC-HB. At these optimum conditions for removing BR28 by adsorption method using GAC$\mathrm{HB}$, dye in wastewater was completely removed.

Adsorption dynamics: The kinetic rate constant for adsorption of BY28, $\mathrm{k}_{\mathrm{ad}}$, was determined using Lagergren's equation ${ }^{6,15}$ :

$$
\log \left(\mathrm{q}_{\mathrm{e}}-\mathrm{q}\right)=\log \mathrm{q}_{\mathrm{e}}-\frac{\mathrm{k}_{\mathrm{ad}}}{2.303} \mathrm{t}
$$

where $\mathrm{q}_{\mathrm{e}}$ and $\mathrm{q}$ (both in $\mathrm{mg} / \mathrm{g}$ ) are the amounts of dye adsorbed at equilibrium and at any time, $\mathrm{t}$, respectively. A straight line plot of $\log \left(\mathrm{q}_{\mathrm{e}}-\mathrm{q}\right)$ versus time indicates the applicability of the above equation (Fig. 8).

The value of $k_{a d}$ was calculated from the slope of the respective linear plot:

$$
-\frac{\mathrm{k}_{\mathrm{ad}}}{2.303}=-0.0088 ; \mathrm{k}_{\mathrm{ad}}=20.266 \times 10^{-3} \mathrm{~min}^{-1}
$$

Adsorption isotherm: The analysis of equilibrium data for the adsorption of BY28 was conducted using a linear line from the Langmuir and Freundlich isotherms shown in eqns. 2 and 3 , respectively:

$$
\begin{aligned}
& \frac{C_{f}}{q}=\frac{1}{q_{\max }} C_{f}+\frac{1}{K_{a} q_{\max }} \\
& \log q=\log K_{f}+\frac{1}{n} \log C_{f}
\end{aligned}
$$




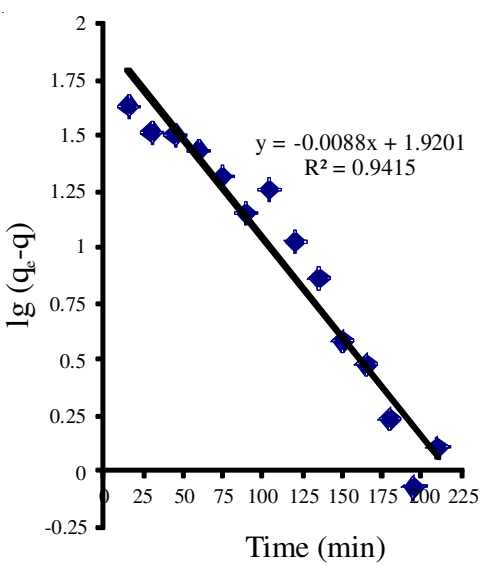

Fig. 8. Lagergren plot for adsorption of BY28

where $\mathrm{C}_{\mathrm{f}}$ (in $\mathrm{mg} / \mathrm{L}$ ) is the equilibrium concentration of BY28; $\mathrm{K}_{\mathrm{a}}$ and $\mathrm{q}_{\max }$ are the Langmuir constants related to the capacity and energy of adsorption, respectively. $\mathrm{K}_{\mathrm{f}}$ and $\mathrm{n}$ are the Freundlich constant characteristics of the system.

The linear plots of $\mathrm{C}_{\mathrm{f}} / \mathrm{q}$ versus $\mathrm{C}_{\mathrm{f}}$ and $\log \mathrm{q}$ versus $\log \mathrm{C}_{\mathrm{f}}$ suggest that the above models were applicable to the present system, an indication of monolayer coverage of the adsorbate at the outer surface of the adsorbent (Figs. 9 and 10).

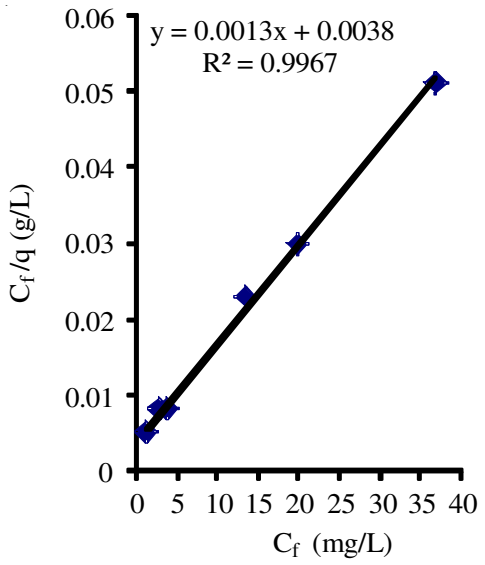

Fig. 9. Langmuir isotherm plot for the adsorption of BY28

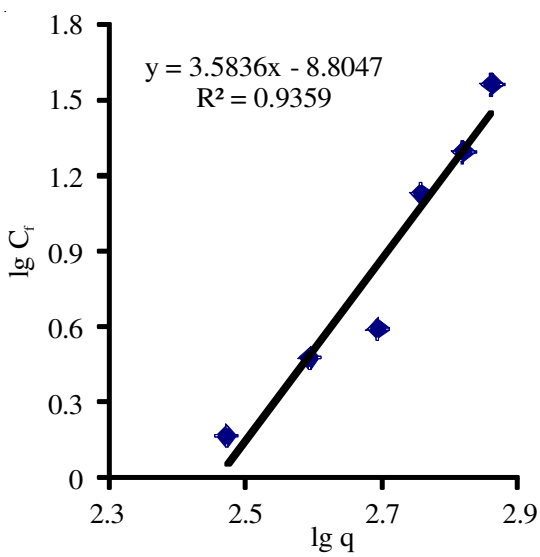

Fig. 10. Freundlich isotherm plot for the adsorption of BY28
The values of $\mathrm{q}_{\max }, \mathrm{K}_{\mathrm{f}}$ and $\mathrm{n}$ calculated from the slopes and intercepts of the linearized plots (Figs. 8 and 9) were $769.23 \mathrm{mg} / \mathrm{g}, 296.96 \mathrm{mg} / \mathrm{g}$ and 3.8285, respectively.

\section{Conclusion}

Basic yellow 28 can be removed from aqueous solution by adsor-ption method using GAC-HB. The adsorption of basic yellow 28 was found to be dependent on initial dye concentration, contact time and adsorbent dosage and $\mathrm{pH}$. At these optimum conditions: $\mathrm{pH} 9$, GAC-HB dose of $0.8 \mathrm{~g} / \mathrm{L}$, contact time for $2 \mathrm{~h}$, basic yellow 28 was completely removed.

\section{REFERENCES}

1. N.D. Vinh, D.S. Duc, D.T. Cuc, H.T.P. Nga and N. Bin, J. Anal. Sci. (Vietnam), 13, 77 (2009).

2. D.S. Duc and D.T.H. Nhung, Vietnam J. Chem., 49, 51 (2011).

3. D.S. Duc, N.T.T. Trang and T.T.H. Trang, In Proceedings of the International Conference on Advanced Wastewater Treatment Technologies and the Potential of Phytoremediation Technology for Wastewater Treatment in Vietnam, Vietnam, pp. 176-182 (2011).

4. M. Anbia and S. Salehi, Dyes Pigm., 94, 1 (2012).

5. N.D. Vinh, D.S. Duc and D.T.Q. Hoa, J. Sci., 22, 237 (2006).

6. B.H. Hameed and M.I. El-Khaiary, J. Hazard. Mater., 154, 639 (2008).

7. N. Yeddou and A. Bensmaili, Desalination, 185, 499 (2005).

8. N. Hoda, E. Bayram and E. Ayranci, J. Hazard. Mater., B137, 344 (2006).

9. D. Sun, X. Zhang, Y. Wu and X. Liu, J. Hazard. Mater., 181, 335 (2010).

10. M. Sarioglu, U. Bali and T. Bisgin, Dyes Pigm., 74, 223 (2006)

11. M. Iranifama, M. Zarei and A.R. Khataee, J. Electroanal. Chem., 659, 107 (2011).

12. A. Olgun and N. Atar, J. Hazard. Mater., 161, 148 (2009).

13. M.K. Purkait, A. Maiti, S. DasGupta and S. De, J. Hazard. Mater., 145, 287 (2007).

14. S.D. Khattri and M.K. Singh, Water, Air Soil Pollut., 120, 283 (2000).

15. S.H. Lin and C.L. Lai, Water Res., 34, 763 (2000).

16. V. Gomez, M.S. Larrechi and M.P. Callao, Chemosphere, 69, 1151 (2007).

17. J. Yener, T. Kopac, G. Dogu and T. Dogu, J. Colloid Interf. Sci., 294, 255 (2006). 